\title{
PEER FEEDBACK ON WRITING SKILLS: PERCEPTIONS OF PAKISTANI ESL POSTGRADUATE STUDENTS
}

\author{
Muhammad Fareed \\ Assistant Professor, \\ Department of Humanities, NED University of Engineering \\ \& Technology, \\ Sindh, Pakistan \\ Email: darfarid@neduet.edu.pk

\section{Ufaq Binte Jamal} \\ Visiting Faculty, \\ Department of Education, Bahria University Karachi, \\ Sindh, Pakistan \\ Email: ufaq_jamal@yahoo.com

\section{Rehmat Ali Yousaf Zai} \\ Research Scholar, \\ Department of Humanities, NED University of Engineering \\ \& Technology, \\ Sindh, Pakistan \\ Email: rehmatyousafzai1@ gmail.com
}

\begin{abstract}
Peer feedback is considered a reliable method in developing the learner's English language writing skills (Falchikov, 2005; Goldfinch, 2000; Moshontz, \& Cooper, 2017; Sanchez, Atkinson, Koenka). It provides a collaborative learning environment, fosters learners' autonomy and reduces anxiety among students (Phillipson, 2007; Richards\& Schmidt, 2010; Stubb, 2013). Nevertheless, the use of peer feedback to improve ESL learners' writing skills is a multifaceted process and needs pre feedback assistaance. The efficacy of peer feedback depends on a range of factors such as the learning setting, the learner, and the assessment procedure itself (Ossenberg, Henderson, \& Mitchell, 2018). Various studies have suggested positive perceptions of peerfeedback (Rotsaert, Panadero \& Schellens, 2018; Vanderhoven, Raes, Montrieux, Rotsaert \& Schellens, 2015). This study aimed to take the perceptions of Pakistani Postgraduate ESL learners' about peer feedback on their writing skills. Before data collection, four formal feedback training sessions were conducted. This involved the participants who received peer feedback on their writings in the class. Data for this study were collected from fourteen Pakistani postgraduate level ESL students through
\end{abstract}


two semi-structured focus group interviews. Before data collection, tool validation was obtained through self and expert validity procedures. The interviews were recorded and transcribed. The transcriptions were shared with the participants before data analysis. Thematic analysis of the collected data was carried out to teach the findings. The findings suggested that collaborative learning environment and peer feedback develop a sense of responsibility, learners' autonomy, critical and analytical skills in students. The analysis of peer feedback further revealed students' biases, non-serious attitude and lack of peer feedback skills among the learners.

\section{KEYWORDS}

Feedback, Peer Feedback, writing skills, ESL context, written feedback in Pakistan

\section{INTRODUCTION}

The diverse digital life has created new forms of communication and social contact among individuals through online and offline means. Innovations in the bulk of disciplines supported by multimedia devices have changed forms and the progression of linguistic communications. This platform has transformed communications links simpler, cheaper, faster, and free of geographical and temporal limitations. Consequently, this surge has increased the significance of English language skills to an extent that English has now become a global lingua franca (Pennycook, 1994; McKay, 2002; Tarone, 2005; Sharifian, 2009; Kilickaya, 2009; Dastgoshadeh and Jalilzadeh, 2011) and continues to develop (Kirkpatrick and Sussex, 2012). Due to its overarching influence in diverse fields, many people around the world acknowledge its Social, economic and educational benefits (Euromonitor, 2010; Power and Shrestha, 2010).

Because of its greater significance and global lingua franca, the English language is used extensively in academic and professional communication in Pakistan (Farooq, Hassan \& Wahid, 2012). It is used for the accomplishment of many purposes in society (Coleman, 2010; Dar \& Khan, 2015; Khan, 2011; Malik, 1996; Mansoor, 2005; Mehboob, 2002; Rahman, 2004). Various studies have reported that effective communication in academic and professional contexts is based on a good command of English language skills (Asif, 2010 cited in Dar, 2014; Hamid, 2007). It has been found that official communication in academic and professional contexts mostly happens in writing (Widdowson, 1984). It is required for: letters, emails, memos, reports etc. and also in the accomplishment of educational purposes like assignments, tests, term papers, projects, and final written examinations. For effective communication, good command of English language writing skills, therefore, holds a great significance to ESL students at the postgraduate level in English as a medium of instruction context, and where students are required to think and communicate in English ((Hamid, 2007; Celce- Murcia, 2001). 
Writing skills is considered central in improving education (Graham \& Harris, 2013). Currently, with an increasing number of universities and multinational companies, writing has become a norm to determine an individual's academic and professional success in all disciplines (Cho \& Schunn, 2007; Graham \& Perin, 2007). However, writing has remained one of the most challenging skills in language learning. Nunan (2001) asserts, "In terms of skills, producing a coherent, fluent, extended piece of writing is probably the most difficult thing there is to do in language. It is something most native speakers never master" (p.217). In ESL and more specifically in EFL contexts, writing is an even more arduous task. Aware of the language difficulties of these students, EFL/ESL writing instructors are struggling hard to enhance the students' writing ability and helping them to develop good writing skills.

In Pakistan, students at the tertiary level majoring in English and other subjects including natural sciences, social sciences, engineering, medicine and management sciences are expected to have developed English language writing skills (Dar, 2014). This could help them to communicate effectively (Shamim, 2010). However various studies have reported the students' low competence in English language writing skills at undergraduate and even at postgraduate level in Pakistan (Khan, 2009; Mashoori \& Iqbal, 2007; Hassan, 2000; Malik, 1996). In many cases even after graduation, the students' inabilities in oral and written discourses of communication suggest their poor English language skills (Khan, 2009). As Malik (1996) states, "A graduate of today lacks competence in written and spoken English" (p.13).

Realizing the significance of the English language in education and workplace contexts, students at the postgraduate level need to acquire an adequate level of writing skills (Asif, 2010; Hamid, 2007; Mashoori, 2007). According to Hassan (2000), students even with good listening and speaking skills were found poor at writing skills. Arguably said, writing is considered more complicated than other language skills even the native speakers face difficulties in learning it (Ferris, 1999). Writing skills entails a well-structured way to present the writer's thoughts in a logical sequence and comprehensive manner (Braine \& Yorozu, 1998).

In Pakistan, students face numerous challenges to develop writing skills. Dar (2014) and Shamim (1996) have listed the following problems: lack of trained English language teachers, inappropriate teaching materials, poor examination system, large classes, old methods of English language teaching and lack of resources in English language classrooms. Shamim (1996) reports that providing feedback to each student in large classes is a difficult task to achieve. Consequently, students with poor feedback are unable to develop their writing capabilities. Some other difficulties that Pakistani students face include lack of vocabulary, weak grammatical structures, poorly organized, poorly structured and illogical sequence in writing with inherent difficulties 
for readers in understanding the overall content and theme (Farooq, Uzair-ul-Hassan \& Wahid 2012). Aronoff \& Rees- Miller (2007) have further pointed out that, "the most common problems of students in ESL/EFL writing profiles are related to poor content, organization, language use, vocabulary, and the mechanics of writing"( $p$, 127).

\section{LITERATURE REVIEW Feedback}

For the past two decades, feedback has extensively been applied as a learning tool in ESL/EFL writing instruction (Zhao, 2010). Feedback can be provided orally and in writing as well. In written feedback, learners however receive detailed and explicit comments on their drafts (Rollinson, 2005). Feedback refers to the kind of information provided orally or in writing to inform students on their real state of learning, understanding and performance (Narciss, 2008; Hattie and Timperly, 2007). Winne and Butler (1994) assert, "feedback is information with which a learner can confirm, add to, overwrite, tune, or restructure information in memory, whether that information is domain knowledge, metacognitive knowledge, beliefs about self and tasks, or cognitive tactics and strategies" (P.5740). The instructional purpose of feedback is to deliver information precisely targeted to overcome the gap between the current level of understanding and the target level of understanding (Sadler,1989). To overcome this break, different affective methods are employed such as greater efforts, engagement and motivation. This gap can also be reduced through different cognitive steps, like restructuring, understandings, informing students that they are correct or incorrect, providing additional knowledge, suggesting directions for improvement, and employing substitute ways to understand (Hattie \& Timperly, 2007).

Feedback is considered a central pedagogic practice in teaching (Hyland, 1998; Hyland and Hyland,2001; Hong, 2004; Bitchener, 2008; Ferris, 2006; Make, 2009). It has been found one of the core component to evaluate the students' learning performance (Mohammad, Jawawi, Matzin, Shahrill, Jaidin, Mundia\&Shamsu,2017; Ghaicha, 2016; Botty \& Shahrill, 2015; Topping, 1998). Studies conducted on the significance of feedback suggest that good pedagogy is highly dependent on good feedback from its source teachers or peers. Alongside several kinds of feedback in the class such as teacher feedback, peer feedback, and conferencing, other methods such as recorded commentaries and computer-based responses are also employed. It is important to share that feedback has an essential role in the kind of scaffolding that learners require to decrease or bridge gaps in their learning process (Musa et al., 2012). Various studies have reported the significance of feedback in developing L1 and L2 writing skills (Mory, 2003; Narciss\& Huth, 2006; Nicole and Macfarlane-Dick, 2006).

\section{Teacher's Feedback}


It refers to "all responses that a teacher makes on a student's draft including shorthand symbols, punctuations markers, the grade earned, and in-text as well as end comments" (Lee \& Schallert, 2008b, p.507). Teacher's feedback has a significant contribution in enhancing students' writing skills, especially in second or foreign language writing as it provides a valuable opportunity for contextualized instructions(Ferris \& Hedgcock, 2014; Ferris, 1995; Saito, 1994; Goldestin, 2004). The kind of input provided by teachers helps learners with correctness, accuracy and level of achievement in learning (Mottet, 2008; Hattie and Timperly, 2007). It is however significant to mention that learners in response to teachers' feedback vary greatly in their preference. Some prefer feedback almost in every aspect of their writing, others pay attention to form, and some are more worried about the content (Cohen, 1987; Ferris, 1995; Hedgcock \& Lefkowitz, 1996; Hyland, 1998; Leki, 1991). Some students prefer feedback at the error level more useful than feedback on content (Hedgcock \& Lefkowitz, 1996; Saito, 1994).

\section{Benefits of Teachers' Feedback}

Numerous studies on writing instructions suggest that students prefer teacher feedback over peer feedback (Ren \& Hu, 2012; Yang et al., 2006; Zhao, 2010). Various studies have emphasized the positive impact of teachers' feedback (Ferris, 2004; Ferris \& Roberts, 2001; Zhang, 1995). Teacher' feedback is considered beneficial for low proficiency learners. It helps in students' motivation and encouragement (Jalalifarahani\&Azizi, 2012; Yang, 2006; Ferris, 2001; Paulus, 1999). Teacher's Feedback is usually aimed to focus on progress rather than deficiency. Based on motivation and the right way in which they can improve, teachers usually encourage students to believe in their abilities. By creating a culture of self-reflection, teachers attempt to motivate students to trust that they can improve by comparing their previous performance. Feedback however differs across cultures. In Chinese, Iranian, Saudi and a few other Asian cultures, students acknowledge the teacher as their preferred agent and a more reliable source of feedback (Jalalifarahani\&Azizi, 2012).

\section{Criticism on Teachers' Feedback}

A large body of research has outlined issues with teacher feedback (Zhao, 2010; Lee \&Schallert, 2008a, 2008b; Yang et al., 2006). It has been found that teacher feedback is more concerned with the writing mechanics like spelling, punctuation, and grammar rather than aspects of content (Lee, 2014; Ferris et al., 2011; Montgomery \& Baker, 2007; Liu \& Hansen, 2002). It was also found that teachers' feedback is timeconsuming specifically in large classes where it is difficult to provide individual feedback (Yang, Badger \& Yu, 2006; Kim and Kim, 2005; Rollinson, 2004). In teachers' feedback, higher-achieving students seem to respond positively whereas lower-achieving students feel nervous (Guénette, 2007). Moreover, students who frequently receive feedback from the teachers are prone to write for the teacher and 
not for themselves (Hattie and Timperely, 2007). (Tsui \& $\mathrm{Ng}, 2000$ ) found that all learners prefered teacher feedback to peer feedback. Their assertion was that teacher is the only source of authority and well qualified to provide suitable comments.

\section{Peer Feedback}

The term peer feedback is widely interpreted. Generally said, it is referred to as peer review, peer response, peer editing, and peer evaluation. It is also defined as the "use of learners as sources of information and interactants for each other in such a way that learners assume the roles and responsibilities normally taken on by a formally trained teacher, tutor, or editor in commenting on and critiquing each other's drafts in both written and oral formats in the process of writing" (Liu and Hansen, 2002:1). Vygotsky's sociocultural theory carries a theoretical stance to rationalize the claims. He believes that the mind grows through one's interaction in the context (Vygotsky, 1978). He further asserts that learning is a socio-cognitive process with a focus on learning through interaction in a social context. Peer engagement, therefore, allows learners to reconstruct knowledge and develop understanding through mutual communication and exchange of thoughts (Liu et al., 2001). A common feature of peer feedback is to evaluate peers' works. This helps students to monitor and reflect on their current learning (Tsivitanidou et al., 2018; Nicol 2011; Cartney 2010; Logan, 2009; Kurzel, 2008; Liu and Carless 2006).

\section{Peer feedback in Writing}

Since writing skills are considered a socio-cognitive process (Hyland \& Hyland, 2001). Good writing skills are therefore based on the kind of feedback provided (Duncan, 2007). With this, some researchers came to believe that peer feedback plays a vital role in developing students' writing skills (Plutsky \& Wilson, 2004; Topping et al., 2000). In a study conducted on the comparative effects of peer-directed and teacher feedback, the writing proficiency of the participants suggested that peer feedback offers a feasible method to improve learners' writing skills (Richer, 1992). In a comparative analysis of three teaching writing skills methods, it was found that peer feedback greatly facilitates students in developing their writing skills (Plutsky \& Wilson, 2004). Since learners are supposed to learn more about writing skills and revision strategies by reading others' drafts critically peer feedback, engages learners in critical assessment of peer text. As a learning strategy, students consider peer feedback as useful as teacher feedback which further makes them autonomous writers (Maarof et al., 2011; Jacobs et al.; 1998Wakabayashi, 2013). Considering peer feedback potential in tertiary education, Topping (1998) argued that peer feedback in writing "appears capable of yielding outcomes at least as good as teacher assessment and sometimes better" (p. 262). Highlighting the effectiveness in developing writing skills, Liu and Hansen (2002) claimed that peer feedback activities in L2 writing contribute to students' cognitive, affective, social-cultural, and linguistic growth. Therefore in developing 
writing skills, the peer correction technique helps learners to know their problems from a less anxiety-provoking party which makes learning easier (Ho, 2015; Zhao, 2014; Ge, 2011; Min, 2005, 2006\&2008).

\section{Advantages of Peer Feedback}

As a social activity with an emphasis on learners' autonomy, peer review provides good pedagogical insights about writing (Breuch, 2004). Graham and Perin (2007) revealed, "collaborative arrangements where students help each other with one or more aspects of their writing had a strong and positive impact on writing quality" (p. 463). Several studies have stated the advantages of peer correction (Badger \& Yu, 2006; Berg, 1999; Hu, 2005; Liou \& Peng, 2009; Min, 2005; Paulus 1999; Rahimi, 2013; Rollinson, 2005; Yang \& Min 2006; Zhao, 2014). As a learner-centred technique, peer feedback motivates the learner to join peer activities and makes them autonomous learners (Hyland, 2000). Peer feedback develops confidence, overcome writing apprehension and providing a social context for writing. It develops critical thinking, fostering learner autonomy and provides a forum for social contact among learners (Lundstrom\& Baker, 2009; Min, 2006; Rollinson, 2005; Yang, Badger \& Yu, 2006). The practice of peer feedback permits learners to receive individual explanations as well as gives them greater chances to rehearse and grow multiple language skills (Lundstrom \& Baker, 2009). Peer feedback is considered a multi-skill nature of the exercise, it, therefore, allows students to recognize the individual strengths and weaknesses in teamwork, analysis, writing and editing thus diversify the learning and supporting the learning requirements of the individual learners (Vickerman 2009).

\section{Disadvantages of peer Feedback}

Although peer feedback has been acknowledged as the most effective technique for its socio-cognitive, affective and methodological benefits, yet this technique has certain limitations. To keep group harmony, some students overrule the errors made by their classmates because correcting classmate's errors might damage their relationship. For example, in Nelson's study (1996) the participants were found to have avoided critical comments while reviewing their friends' drafts of writing. It was also found that lowerachieving student after getting corrected by higher-achieving students feel offended. In such cases, students prefer their drafts to be reviewed by the teachers themselves (Jeremy Harmer, 2004). Moreover, some students feel reluctant and do not want their friends to know about their weaknesses because it amounts to their self-esteem (Jeremy Harmer, 2004). Also, it was found that some students do not believe in peers' knowledge and as such attempt to avoid peer' review (Macdonca\& Johnson, 1992). Providing critical feedback is a more demanding task, it might lead to rejection by peers when it is not practised well (Emerson, 1954; Lauderdale, 1976; Levine, 1980; Wiggins, Dill, \& Schwartz, 1965). Saito and Fujita (2004) have reported several factors 
associated with peer feedback such as purpose, friendship and reference. Peer feedback works well only when it suits the students' needs, also when there is a supportive environment in the classroom (SimaSengupta, 1998). Anonymity is however considered a feature that may reduce potentials threats of fears and bias and allows students to be critical and honest (Cho and Schunn, 2007; Zhao, 1998).

\section{Effective Feedback}

Feedback is an integral part of instructions (Mohammad et al., 2017; Ghaicha, 2016; Botty\&Shahrill, 2015; Sadler, 1998). Feedback is considered effective if it is frequent and balanced, precise and clear, contains the element of praise and critique and also offers suggestions for improvements (Khowaja, Raisa, Lakhani, Rizvi, \&Saleem. 2014). Peer review has been acknowledged as the most effective technique in developing the students' writing skills (Berg, 1999; Chaudron, 1984; Min, 2006; Mittan, 1989; Paulus 1999; Rollinson, 2005).

\section{RESEARHCH OBJECTIVE}

1. To record perceptions of Pakistani ESL postgraduate students about peer feedback on writing skills

\section{RESEARHCH QUESTION}

1. What are perceptions of Pakistani ESL Postgraduate students about peer feedback on writing skills?'

\section{RESEARCH METHOD}

This qualitative study constituted fourteen post-graduate students $(\mathrm{N}=14)$ with the further bifurcation of six male $(\mathrm{N}=6)$ and eight females $(\mathrm{N}=8)$ enrolled in a postgraduate programme at a public sector university of Karachi in Pakistan.

\section{Instruments}

Data were collected through a semi-structured focus group interview. The interview protocol was developed. Before data collection, self-validity and expert validity of the tool was achieved. Written consent of the participants was also obtained. Data collected through interviews were recorded and transcribed. The transcriptions were shown to the participants for member-checking validity (Cohen, Manion \& Morrrison, 2010).

\section{Procedure}

In the first phase, the participants were given a three-hour training session on feedback. The participants were guided through rubrics in giving and receiving feedback from peers. This was followed by assigning writing tasks. Third, the write-ups from all participants were collected and were assigned codes. These write-ups were again 
administered to participants for their feedback with further emphasis that no participant has received his or her write-up. Later, the write-ups were returned to their respective writers. Four sessions of writing and peer feedback process were conducted before data collection through interviews.

\section{Data Analysis}

Data collected through focus group interviews were thematically analysed. Before data analysis, codes were assigned to participants. Female participants were given FP followed by a numeral and Male Participants were assigned MP along with a numeral.

\section{Theme 1: Participants' Exposure to Peer Feedback}

Most of the participants' responses suggested that they practised peer feedback at postgraduate level for the first time during this study: "in my academic career, it happened for the first time to have practised peer feedback at MS level and I found it an extremely good learning experience" (MP, 1; FP, 3; MP, 4).

\section{Theme 2: Appropriate level to Practice Peer Feedback in ESL Class}

It was found that secondary or higher secondary level is a highly appropriate level at which peer feedback can be introduced to ESL learners: "It's a useful technique and should be applied at Matric (grade 10) and intermediate (grade 11-12) level (MP, 2\& 4)". It was also found that peer feedback is more useful at the tertiary level, "In my opinion, it can be used at even tertiary level because it develops analytical and critical skills" $(M P, 3)$. Some of the participants' responses also suggest that peer feedback is relevant at all levels provided the learners are trained "it should be used at all levels" but "students should be properly trained" (FP, 7 \& MP, 2, 3).

\section{Theme 3: Strengths of peer feedback}

Concerning the strength of peer feedback, the responses of participants outlined the following benefits: learners' autonomy, students' sense of responsibility, collaborative learning and friendly classroom environment, creativity, developing critical and analytical skill among students, motivation and immediate feedback from peers: "It fosters learners autonomy and sense of responsibility"(FP, 4; FP, 1; MP, 4; MP, 5). $\mathrm{PF}$ "creates a friendly environment and collaborative learning in class" (FP, 5; FP, 7; MP, 1; MP, 6; MP, 7). It develops cognitive skills like creativity, confidence, sense of responsibility, sense of maturity and the logical understanding of things "'(MP, 3; MP, 4; FP, 7). Peer feedback provides a new genre for students to think differently as it provides an environment where students get multiple ideas from peers while reading each other write-ups." (FP, 1; MP, 2 \& MP, 3).

\section{Theme 4: Challenges to implement peer feedback strategy}


With regard to challenges in implementing PF, it was found that PF has remained unpractised due to certain constraints including lack of training, poor assessment due to inherent biases among students to override and compete others: "Biasness is a big constraint in passing critical and judicial comments on peers' write- up. Moreover, cultural, linguistic, and gender variations have also negative effects that could otherwise make PF a more positive learning technique" (MP, 7). The responses also suggest a lack of awareness about the significance of constructive feedback, more reliance on teachers' feedback, learners' non-serious approach towards peer feedback, lack of objectivity, time management and gender differences (MP, 2\& FP, 1\& 5). Concerning teachers' centred approach, the participants shared, "since long we are accustomed to teacher feedback in classroom instructions, so switching from teacher to peer feedback is itself challenging"(FP, 3; MP, 1). It was further revealed that in ESL contexts like Pakistan, most of the students prefer and value teachers' feedback more than their peer feedback "our environment is not conducive enough for PF therefore students believe in teacher feedback, view teacher as the only authority to judge their work",(FP, 3; FP, 5; MP, 3; MP, 4; MP, 6; MP, 7). Lack of training, sense of responsibility and also in an attempt to maintain group harmony, students don't evaluate each others' drafts critically "due to lack of maturity and sense of responsibility, students pose a critical question to each other regarding their feedback inside \& outside the class (FP, 4; MP, 5). It was also found that "most of the students in peer review activities don't read their fellows write-up properly, even those who read have been found non-serious in commenting and critiquing. Because they are neither adequately trained to judge others' work nor they demonstrate honesty in passing unaffected remarks"'(FP, 4 \&7; MP, 2).

\section{Theme 5: Ways of making peer feedback more effective}

The participants suggested four different ways for making peer feedback an effective enabling strategy for better learning outcomes: "adequate training, proper guidance by the teachers, frequent peer feedback activities and developing positive sense about $P F$ in the class can make peer feedback more effective"(MP, 1; FP, 3 \&7).

\section{DISCUSSION}

The purpose of this qualitative descriptive study was to explore the perceptions of ESL tertiary level students about peer correction. The analyses of participants' responses suggest that peer feedback shall be introduced at the secondary level. "It's a useful technique and should be applied at Matric (grade 10) and intermediate (grade 11-12) level (MP, $2 \& 4$ )'”.Logically said, this might cultivate a culture for enhanced benefits at the upper level in the academic row. Since peer feedback is considered a sociocognitive technique, students develop their cognitive abilities through mutual interaction with more knowledgeable peers. When students are actively engaged in collaborative activities, they extend their understanding through scaffolding by another 
adult and more experienced peer (Vygotsky, 1978). It was found that participants have never experienced peer correction at any level of education: "in my academic career, it happened for the first time to have practised this activity at MS level and I found it an extremely good learning experience" (MP, 1; FP, 3; MP, 4). In teacher's feedback, students do not develop their autonomous output skills (Hojeij and Hurley, 2017). The insights of this study suggest that:: "peer feedback fosters learners autonomy and sense of responsibility"(FP, 4; FP, 1; MP, 4; MP, 5). It raises awareness about the writing strengths and weaknesses and fosters ownership, a sense of responsibility and independence (Tsui \& Ng, 2000; Yang et al., 2008). In peer correction, while discussing fellow student's written drafts and reflecting on errors can improve their writing skills, develop assessment skills, and nurture cooperative learning (Alqassab, Strijbos \& Ufer, 2018; Min, 2006; Smith, 2017). With increasing benefits, peer feedback is important for the improvement in writing or editing processes (Wang, 2014). This further reveals that peer feedback is relevant at all levels provided the learners are trained "it should be used at all levels but students should be properly trained" (FP, $7 \&$ MP, 2, 3). Since students are not considered knowledge sources, as such they are not expected to be an expert reviewer and editor, they need training on how to edit: "most of the students in peer review activities don't read their fellows write-up properly, even those who read have been found non-serious in commenting and critiquing. Because they are neither adequately trained to judge others' work nor they demonstrate honesty in passing unaffected remarks "(FP, 4 \& 7; MP, 2). Regarding challenges in practising peer correction, certain constraints were found: "Biasness is a big constraint in passing critical comments on peers' write- up. Also, cultural, linguistic, and gender variations have a negative impact in implementing peer feedback" (MP, 7) How to make peer feedback effective learning tool, responses of the participants suggest four different ways to make peer feedback an effective enabling strategy: "training, rich input and guidance by teachers, enhanced frequency of peer feedback, and developing positive attitude"'(MP, 1; FP, 3 \& 7). Peer feedback can be effective if students are properly trained, overcome biases, develop a sense of responsibility in giving and receiving feedback from their peers (Kunwongse, 2013; Lim, 2010). This could bring a positive change in switching learners from teacher feedback to learners' feed aback (Kunwongse, 2013; Morra\& Romano, 2009). There may be some resistance and peers may not accept the comments from each other (Strijbos, Narcisse \& Dunnebier, 2010). This opposition can be overcome through scaffolding which can be described as teaching support that helps students develop basic peer review skills, and as the learners can become capable reviewers in achieving new tasks, help shall be gradually reduced (Sun, Wang \& Chan, 2011).

\section{CONCLUSION}

Given the recurring themes evolved from the analysis of participants' responses, this study concludes that peer feedback is a significant learning tool in developing the 
students' writing skills. Since writing is a complex process that constitutes five basic elements: content, organization, vocabulary, language use, and mechanics. Good writing skills are therefore based on rich input. This further provides sufficient justification for peer review, editing and correction. However, despite the beneficial effects of this experience, peer correction should not be considered an easy option for students. Considerable efforts are required to prepare students for peer correction and to guarantee that the experience is both useful and helpful. Teachers must be watchful of the widespread range of possible disadvantages when conducting peer review activities. Perceived fears like students with poor command of language might feel reluctant to share their work with their classmates. Moreover, affective factors like religious, cultural and ethnicity are likely to interfere and some students may find it problematic to work with opposite-gender peers. Potential threats of bias can't be ruled out. It is also important to recognise different types of biases that may unduly influence feedback from peers. Observations suggest that objective reviewing and assessing was problematic for some students, consequently, negative feedback was given because the peer disagreed with the arguments put forth in the write-ups. It was also found that male students took an authoritative stance than female students. With these potential pitfalls, responsibility comes on teachers to ensure that students are trained enough and sufficiently motivated to actively involve in the feedback process by evaluating the quality of the work, and they also acknowledge that there is an adequate explanation for the comments and suggestions put forward. The focus of this study was Postgraduate, MS level. The findings of this study may provide useful insights to other researchers interested in probing peer feedback at other levels of education.

\section{RECOMMENDATIONS}

Peer feedback is considered a useful learning technique in helping the student to overcome their writing apprehensions, foster autonomy and develop their critical and analytical skills in writing at school, undergraduate and postgraduate levels. This study recommends that peer feedback shall be made part of the curriculum as a mandatory academic activity rather than being practised randomly. Comparative analysis of studies conducted to explore the perceptions of learners suggested that students had negative perceptions of peer feedback carried out as casual activity. It was revealed that peer feedback is valuable if it had been an integral part of the course (Kashimura (2007, as cited in Hirose, 2008). Conversely, in Hirose's (2008) study, peer feedback was practised every week as an essential part of the writing course. Further, according to the study learners had a positive attitude towards every step of peer feedback during reading the peer write up, comments, and talking to their peers about the comments. For better learning outcomes, this study also suggests training, guidance and practice before and during feedback sessions. This would help student well prepared in providing constructive feedback. Various studies suggest that well-prepared learners have been found effective peer readers than those who have been less prepared (Berg, 
1999; Min, 2006; Stanley, 1992; Zhu, 1995). A study compared the learners trained in providing peer feedback with those less trained (Berg, 1999; Stanley, 1992), and (Min, 2006; Zhu, 1995) compared the students before and after peer feedback training found that training has a positive influence in preparing learners on commenting and critiquing their peers' written drafts. Although various peer feedback methods have commonly been used, however, written peer feedback has been found superior to oral peer feedback because reviewers have sufficient time to review and provide valuable comments (Baker, McQuade, Sommers, \& Tratner, 1989; Huff \& Kline, 1987). Given the students' perceptions, this study recommends written feedback because oral feedback not only leads to reduced consideration of the comments but it also puts cognitive pressure on less proficient L2 learners (Ferris, 2010). For enhanced benefits, this study further recommends that the strength of the classroom shall be reduced to a manageable size with emphasis on practising peer review activities. Moreover, students shall be encouraged to provide feedback as specific and accurate as possible. Moreover making peer feedback as a graded activity may motivate learners to take the peer feedback more seriously (Ferris, 2003; Ferris \& Hedgcock, 2005; Hyland, 1996; Mittan, 1989).

\section{REFERENCES}

Aronoff, M., \&, Rees-Miller, J. (2007). The handbook of linguistics. Oxford: Blackwell.

Badger, R., \& White, G. (2000). A process-genre approach to teaching writing. ELT journal, 54(2), 153-160.

Alqassab, M., Strijbos, J. W., \& Ufer, S. (2018). Training peer-feedback skills on geometric construction tasks: role of domain knowledge and peer-feedback levels. European Journal of Psychology of Education, 33(1), 11-30.

Berg, C. (1999). The effects of trained peer response on ESL students' revision types and writing quality. Journal of Second Language Writing, 8(3), 215- 241.

Braine, G., \& Yorozu, M. (1998). Local area network (LAN) computers in ESL and EFL writing classes: Promises and realities. JALT Journal, 20(2), 47-59.

Chaudron, C (1984) Evaluating Writing: Effects of feedback on revision. RELC Journal 15(2): $1-14$.

Connor, U, Asenavage, K (1994) Peer response groups in ESL writing classes: how much impact on revision? Journal of Second Language Writing 3(3): 257-76.

Dar, M. F., \& Khan, I. (2014). Oral communication apprehension among undergraduate engineering students in Pakistan. Journal of Education \& Social Sciences, 2(2), 144153.

Dastgoshadeh, A., \& Jalilzadeh, K. (2011). Language Loss, Identity and English as an International Language. European Journal of Social sciences, 21(4), 659665.

Farooq, M. S., Uzair-Ul-Hassan, M., \& Wahid, S. (2012). Opinion of second language learners about writing difficulties in English language. South Asian Studies, 27(1), 183.

Falchikov, N. (2005). Improving assessment through student involvement: Practical 
solutions for aiding learning in higher and further education. New York: Routledge Falmer.

Falchikov, N., \& Goldfinch, J. (2000). Student peer assessment in higher education: A metaanalysis comparing peer and teacher marks. Review of Educational Research, 70(3), 287-322.

Ferris, D. R. (1995). Can advanced ESL students be taught to correct their most serious and frequent errors? CATESOL Journal, 8, 41-62.

Ferris, D. (1997). The influence of teacher commentary on student revision. TESOL Quarterly, 31(2), 315-339.

Ghaicha, A. (2016). Theoretical framework for educational assessment: A synoptic review. Journal of Educationand Practice, 7(24), 212-231.

Goldstein, H. (1994) Recontextualising mental measurement. Educational Measurement: Issues and Practice, 13, 16-19. (A detailed examination of test equating and related procedures.)

Goldstein, L (2004) Questions and answers about teacher written commentary and student revision: teachers and students working together. Journal of Second Language Writing 13(1) 63-80.

Graham, S., \& Harris, K. (2000). The role of self-regulation and transcription skills in writing and writing development. Educational Psychologist, 35(1), 3-12. doi: 10.1207/S15326985EP3501_2

Graham, S., \& Perin, D. (2007). A meta-analysis of writing instruction for adolescent students. Journal of Educational Psychology, 99(3), 445-476. doi: 10.1037/0022-0663.99.3.445.

Guénette, D. (2007). Is feedback pedagogically correct? Research design issues in studies of feedback on writing. Journal of Second Language Writing, 16, 40-53.

Hamid, A. (2007). Teaching Creative Writing through Pictures (unpublished Master"s thesis). AllamaIqbal Open University, Islamabad.

Hashemi, M (2011). Language stress and anxiety among the English language learners. Procedia - Social and Behavioral Sciences 30, 1811-1816.

Hattie, J., \& Timperley, H. (2007). The power of feedback. Review of Educational Research, $77(1), 81-112$.

Hedgcock, J., \& Lefkowitz, N. (1994). Feedback on feedback: Assessing learner receptivity in second language writing. Journal of Second Language Writing, 3, 141-163.

Hyland, F. (1998). The impact of teacher written feedback on individual writers. Journal of Second Language Writing, 7(3), 255-286.

Hyland, F., \& Hyland, K. (2001). Sugaring the pill: Praise and criticism in written feedback. Journal of Second Language Writing, 10, 185-212.

Jalalifarahani, M., \& Azizi, H. (2012). The efficacy of peer vs. teacher response in enhancing grammatical accuracy \& general writing quality of advanced vs. elementary proficiency EFL learners. International Conference on Language, Medias and Culture, 33.

Kamimura, T. (2006). Effects of peer feedback on EFL student writers at different levels of English proficiency: A Japanese context. TESL Canada Journal, 23(2), 12.

Kilıçkaya, F. (2009). World Englishes, English as an International Language and Applied Linguistics. English Language Teaching ELT, 2(3). 
Kunwongse, S. (2013). Teaching strategies that help improve students peer editing skills. Language Institute, Thammasat University

Lundstrom, K., and W. Baker. 2009. "To Give Is Better than to Receive: The Benefits of Peer Review to the Reviewer's Own Writing." Journal of Second Language Writing 18 (1):30-43. doi: 10.1016/j.jslw.2008.06.002.

Lee, G., \&Schallert, D. L. (2008a). Meeting in the margins: Effects of the teacher-student relationship on revision processes of EFL college students taking a composition course. Journal of Second Language Writing, 17(3), 165-182. doi:10.1016/j.jslw.2007.11.002

Lee, G., \&Schallert, D. L. (2008b). Constructing trust between teacher and students through feedback and revision cycles in an EFL writing classroom. Written Communication,25(4),506-537.doi:10.1177/0741088308322301.

Lee, I. (2014). Revisiting teacher feedback in EFL writing from sociocultural perspectives. TESOLQuarterly,48(1),201-213.doi:10.1002/tesq.153

Lundstrom, K., \& Baker, W. (2009). To give is better than to receive: The benefits of peer review to the reviewer's own writing. Journal of Second Language Writing, 18, 3043.

Mittan, R. (1989). The peer review process: Harnessing students' communicative power. In Johnson, D. and Roen, D. (Eds.). Richness in writing: Empowering ESL students (pp. 207-219). New York: Longman

Malik, F. 1996. Vie Teaching of English in Pakistan. Lahore: Vanguard.

Mashori, G.M.,\&Iqbal Z. (2007). Teaching the writing of English: Exploring the impact of process approach on the undergraduate students of shah Abdullatif university Khair Pur. English Language \& Literary Forum, 7, 1-26.

Mendonca, C, Johnson, K (1994) Peer review negotiations: revision activities in ESL writing instruction. TESOL Quarterly 28(4): 745-69.

McKay, S. L. (2002). Teaching English as an international language. Oxford: Oxford University Press.

Min, H. T. (2006). The effects of trained per review on ESL students' revision types and writing quality. Journal of Second Language Writing15 (2006), 118-141, doi:10.1016/j.jslw.2006.01.003

Min, H. (2005). Training students to become successful peer reviewers. System, 33(2), $293-$ 308. doi:10.1016/j.system.2004.11.003

Min, H. (2008). Reviewer stances and writer perceptions in EFL peer-review training.English for Specific Purposes, 27(3), 285-305. doi:10.1016/j.esp.2008.02.002

Mohammad, H. H., Jawawi, R., Matzin, R., Shahrill, M., Jaidin, J. H., Mundia, L., \& Shamsu, L. S. (2017).Engaging students' learning with elements of formative assessment.Turkish Online Journal of EducationalTechnology, December 2017

Special Issue for ITEC 2017, 12(1), 281 -290.

Morra, A. M., \& Romano, M. E. (2008).University students' reaction to guided peer feedback of EAP compositions.JCLL, 35 (2008-2009), 19-30.

Narciss, S. (2008). Feedback strategies for interactive learning tasks. In J. M. Spector, M. D. Merrill, J. Van Merrie“nboer, \& M. P. Driscoll (Eds.), Handbook of research on educational communications and technology $\left(3^{\text {rd }}\right.$ ed.). (pp. 125 e143) New York: Erlbaum 
Ossenberg, C., Henderson, A., \& Mitchell, M. (2018). What attributes guide best practice for effectivefeedback? A scoping review. Advances in Health Sciences Education, 1-19.

Panadero, E. (2016). Is it safe? Social, interpersonal, and human effects of peer assessment: A review and future directions. In G. T. L. Brown \& L. R. Harris (Eds.), Human factors and social conditions of assessment (pp. 1-39). New York, NY: Routledge.

Paulus, T. M. (1999). The effect of peer and teacher feedback on student writing. Journal of Second Language Writing, 8(3), 265-289.

Pennycook, A. (2001). Critical applied linguistics: A critical introduction. New Jersey: Lawrence Erlbaum Associates.

Phillipson, R. (1992). Linguistic imperialism. Oxford: Oxford University Press

Rahimi, M. (2013). Is training student reviewers worth its while? A study of how training influences the quality of students' feedback and writing. Language Teaching Research,17(1),67-89.doi:10.1177/1362168812459151.

Rollinson, P. (2005). ELT Journal Volume 59/1 January 2005 (C) Oxford University Press DOI: 10.1093/elt/cci003.

Rotsaert, T., Panadero, E., \&Schellens, T. (2018). Anonymity as an instructional scaffold in peerassessment: its effects on peer feedback quality and evolution in students' perceptions aboutpeer assessment skills. European Journal of Psychology of Education, 33(1),75-99.

Sadler, D. R. (1998). Formative assessment: revising the territory. Assessment in Education, 5(1),77-84.http://dx.doi.org/10.1080/0969595980050104

Sadeghi, K., \& Abolfazli Khonbi, Z. (2015). Iranian university students' experiences of and attitudes towards alternatives in assessment. Assessment \& Evaluation in Higher Education, 40(5), 641665.

Sharifian, F. (Ed.). (2009). English as an international language: Perspectives and pedagogical issues. Bristol: Multilingual Matters.

Strijbos, J. W., \& Wichmann, A. (2018). Promoting learning by leveraging the collaborative nature of formative peer assessment with instructional scaffolds. European Journal of Psychology of Education, 33(1), 1-9.

Sanchez, C. E., Atkinson, K. M., Koenka, A. C., Moshontz, H., \& Cooper, H. (2017). Selfgrading and peergrading for formative and summative assessments in 3rd through 12th-grade classrooms:A meta-analysis. Journal of Educational Psychology, 109(8), 1049.

Shamim, F. (2007). Sustainability of ESP projects: A case study from Pakistan. (Unpublisheddoctoral dissertation). Paper presented at the IATEFL Conference, Aberdeen,19-22 April 2007.

Schmidt, R. A., \& Bjork, R. A. (1992). New conceptualizations of practice: Common principles in three paradigms suggest new concepts for training. Psychological Science, 3(4), 207-217.

Stanley, J. (1992). Coaching student writers to be effective peer evaluators. Journal of Second Language Writing, 1(3), 217-233.

Topping, K. J. (1998). Peer assessment between students in colleges and universities. Review of Educational Research, 68(3), 249-276.

Tsui, A. B. M., \& Ng, M. (2000). Do Secondary L2 Writers Benefit from Peer Comments? Journal of Second Language Writing, 9(2), 147-170. 
Vanderhoven, E., Raes, A., Montrieux, H., Rotsaert, T., \&Schellens, T. (2015). What if pupils can assess their peers anonymously? A quasi-experimental study. Computers \& Education, 81, 123-132

Vickerman, P. (2009). Student perspectives on formative peer assessment: An attempt to deepen learning. Assessment and Evaluation in Higher Educaation, 34(2), 221- 230.

Vygotsky, L.S. (1978). Mind in Society. Cambridge, MA: Harvard University Press.

Wang, J. H., Hsu, S. H., Chen, S. Y., Ko, H. W., Ku, Y. M., \& Chan, T. W. (2014). Effects of a mixed-mode peer response on student response behavior and writing performance. Journal of Educational Computing Research, 51(2), 233-256.

Zhang, S. (1995). Re-examining the affective advantages of peer feedback in the ESL writing class. Journal of Second Language Writing, 4, 209-222. 